\title{
Editorial
}

Dermatology 2006;213:81-82

DOI: $10.1159 / 000093844$

\section{Do the Telangiectases of Hereditary Hemorrhagic Telangiectasia and the Calcinosis, Raynaud's Disease, Sclerodactyly, Telangiectasia Variant of Scleroderma Have a Common Etiology?}

\author{
Irwin M. Braverman \\ Department of Dermatology, Yale Medical School, New Haven, Conn., USA
}

The current hypothesis regarding the pathogenesis of telangiectasia in hereditary hemorrhagic telangiectasia (HHT) centers on the glycoprotein endoglin. Morphologic studies using 3-dimensional reconstruction demonstrate that dilatation of pre-existing post-capillary venules in the absence of inflammation is the earliest detectable finding in HHT [1]. As the cutaneous lesion enlarges, the connecting arteriole becomes dilated and the capillary connection disappears, resulting in an arterio-venous communication.

Endoglin (Eng) haploinsufficiency explains most cases of HHT type 1. Endoglin is an essential component of the endothelial nitric oxide synthase (eNOS) activation pathway where it is an important regulator in the coupling of eNOS activity [2]. With decreased availability of eNOS, there is less production of $\mathrm{NO}$ to produce vasodilatation that modulates the normal vasoconstrictive tone in the microcirculation. In Eng-deficient mice that develop features of HHT, endoglin insufficiency has also been shown to be associated with a disturbance of vasomotor control produced by arteriolar smooth muscle [2]. These findings, coupled with the earlier morphologic studies, likely explain the development of telangiectasia in HHT. The arteriole no longer functions effectively as a resistance vessel producing vasoconstriction when required by microcirculatory dynamics. Such a disturbance results in increased perfusion, with resultant vasodilatation, in the postcapillary venules. With continuous high perfusion, the capillary bed disappears with loss of its resistive function to form a high-pressure arterio-venous communication. In calcinosis, Raynaud's disease, sclerodactyly, telangiectasia syndrome (CRST), studies demonstrate that the telangiectases (telangiectatic mats) are composed only of vasodilated post-capillary venules without inflammatory cells [3] and appear as red, flat polygons, $0.1-1 \mathrm{~cm}$, without any visible intrinsic branches. The telangiectases of HHT are always papular, ranging from less than 1 to $5 \mathrm{~mm}$ and stretching the skin around the lesion makes the vascular tributaries within visible. Winterbauer [4] established the clinical importance of the mats as a sign of the CRST variant of scleroderma. However, he was in error when he stated that the mats were identical in appearance to the lesions of HHT, even though they occurred in the same distribution. However, in 3 of 50 cases of CRST, I have observed telangiectases identical in morphology and distribution to those seen in HHT.

In this issue, Fujimoto et al. [5] report that abnormally elevated levels of soluble endoglin are found in the serum of $35 \%$ of patients with CRST. Confirmation of this observation will implicate endoglin in the pathogenesis of CRST telangiectases and raise the possibilities that endoglin is physiologically defective, leading to a state of haploinsufficiency, or that an overabundance of endoglin is inhibitory, simulating haploinsufficiency. A testable

\section{KARGER}

Fax +4161306 1234

E-Mail karger@karger.ch

www.karger.com
(C) 2006 S. Karger AG, Basel

$1018-8665 / 06 / 2132-0081 \$ 23.50 / 0$

Accessible online at:

www.karger.com/drm
Dr. Iwin M. Braverman

Department of Dermatology, Yale Medical School

333 Cedar Street

New Haven, CT 06510 (USA)

E-Mail irwin.braverman@yale.edu 
hypothesis arises: the rarity of HHT-like lesions in CRST patients may be explained by the usually present Raynaud's phenomenon providing the necessary vasoconstriction through other pathways to overcome the loss of vasoconstrictive tone by endoglin-deficient smooth muscle cells.

A grading scheme to quantify mat telangiectases by number, size, and distribution plus a grading system for Raynaud's phenomenon using parameters of frequency, duration and severity could be correlated with the serum levels of soluble endoglin levels in CRST, diffuse scleroderma, SLE and normal age-matched controls. This would establish more reliably whether and what role endoglin might play in the pathogenesis of CRST and diffuse scleroderma. Would the three patients with HHT-like lesions cited above have no Raynaud's activity? Photographic documentation of the telangiectases observed in the anticentromere-negative and scl-70-positive patients with diffuse scleroderma would preclude errors of misdiagnosis of CRST and diffuse scleroderma in future studies.

\section{References}

1 Braverman IM, Keh A, Jacobson BS: Ultrastructure and three-dimensional reconstruction of the telangiectases of hereditary hemorrhagic telangiectasia. J Invest Dermatol 1990; 95:422-427.

2 Toporsian M, Gros R, Kabir MG, Vera S, Govindaraju K, Eidelman DH, Husain M, Letarte $\mathrm{M}$ : A role for endoglin in coupling eNOS activity and regulating vascular tone revealed in hereditary hemorrhagic telangiectasia. Circ Res 2005;96:684-692.
3 Braverman IM, Keh-Yen A: Ultrastructure and three-dimensional reconstruction of several macular and papular telangiectases. J Invest Dermatol 1983;81:489-497.

4 Winterbauer RH: Multiple telangiectasia, Raynaud's phenomenon, sclerodactyly, and subcutaneous calcinosis: a syndrome mimicking hereditary hemorrhagic telangiectasia. Bull Johns Hopkins Hosp 1964;114:361-383.
5 Fujimoto M, Hasegawa M, Hamaguchi Y, Komura K, Matsushita T, Yanaba K, Kodera M, Takehara K, Sato S: A clue for telangiectasis in systemic sclerosis: elevated serum soluble endoglin levels in patients with the limited cutaneous form of the disease. Dermatoloy 2006; 213:88-92. 